\title{
Whether and How Does Entrepreneurship Education Influence Entrepreneurship of College Students in China?
}

\author{
Miao Li \\ Dongbei University of Finance and Economics \\ Dalian, Liaoning, 116025, China
}

\begin{abstract}
This study examined whether and how entrepreneurship education impacts college students' entrepreneurial intentions in China. A model of regression analysis is used for the data analysis. The results show that the Chinese entrepreneurship education for college students has a positive influence on their entrepreneurial intention, and subjective perception of entrepreneurial feasibility plays a mediating role. However, entrepreneurship education has negligible impact on perceived expectation, which may be the main reason for the low entrepreneurship rate in China. This paper also puts forward implications and suggestions for universities and governments.
\end{abstract}

Keywords-Entrepreneurship Education, Entrepreneurial Intention, Perceived Expectation, Perceived Feasibility

\section{INTRODUCTION}

Although Chinese universities have already developed various forms of entrepreneurship education in recent years, the entrepreneurial behaviors of college students are far from the expectation. According to the statistics by the Ministry of Human Resource and Social Security, college students' entrepreneurship rate is only 1\% in 2014.Although scholars have conducted some researches on the validity of the entrepreneurship education in China, most of them are qualitative studies and the empirical ones are still limited.

In the field of entrepreneurship, entrepreneurial intention is believed to be the best predictor of entrepreneurial behaviors. This study believed that although entrepreneurship education does not result in an obvious increase of college students' entrepreneurial behaviors in the short term, it may significantly impact on the entrepreneurial intention, which could promote future entrepreneurship. So, this paper took the entrepreneurial intention of college students as the research object and explored whether and how entrepreneurship education influences entrepreneurial intention through empirical research. By introducing perceptive feasibility and perceptive expectation as mediating variables, the study tries to find out the path of the impact. This study not only helps us evaluate the effect of Chinese entrepreneurship education more objectively, but also makes up for the lack of empirical researches.

\section{LITERATURE REVIEW AND RESEARCH HYPOTHESIS}

A. The impact of entrepreneurship education on the entrepreneurial intention

With the rapid development of entrepreneurship education all over the world, the impact of entrepreneurship education on entrepreneurial intention has gradually caused the attention of scholars, however, as for the relationship between these two factors, academic circle has not come up with the coincident conclusion. While some studies found that the college students who had accepted the entrepreneurship education were more likely to engage in entrepreneurial activities[1], some other studies pointed out that education not only made no contributions to developing students' entrepreneurial spirit, but also restrained their need for achievements and the propensity of internal locus of control which were the most important personal characteristics for entrepreneurs[2].In China, an important motivation for Chinese government and universities to promote entrepreneurship education is to increase the entrepreneurial activities of college students, and the basic logic behind is that entrepreneurship education has an significant influence on college students' entrepreneurial intention and behaviors, so the paper puts forward the following hypotheses:

H1: Entrepreneurship education will be positively related to college students' entrepreneurial intention.

\section{B. The impact of entrepreneurship education on the perceived expectation and feasibility}

The perceived feasibility refers to the ability and confidence perceived by the potential entrepreneurs when setting up new enterprises. The studies of Fayolle et al. confirmed that university's entrepreneurship education curriculum had positive impacts on the perceived expectation and feasibility for a new business [3]. However, Krueger and Carsrud found that although the entrepreneurship education could enhance people's perceived feasibility, it would reduce their perceived expectation at the same time [4]. This paper believes that experience sharing of successful entrepreneurs in entrepreneurship-related classes may increase the attraction of entrepreneurial activities. Besides, the contents of entrepreneurship courses can improve students' entrepreneurial 
ability and then enhance their perceived feasibility. So, the paper puts forward the following hypotheses:

H2: Entrepreneurship education will be positively related to perceived expectation.

H3: Entrepreneurship education will be positively related to perceived feasibility.

\section{The impact of the perceived expectation and feasibility on entrepreneurial intention}

The study of Shapero and Sokol showed perceived expectation, perceived feasibility and action tendency were three important antecedent variables for promoting the entrepreneurial intention [5], and most of later research confirmed the results. However, there were some studies showed that although perceived expectation had positive impact on entrepreneurship intention, perceived feasibility had no significant influence on it[3][6]. Although there are various research conclusions, this paper argues that the greater attraction of entrepreneurial activities on entrepreneurs, the more confident the entrepreneurs feel about their entrepreneurial abilities, and the more entrepreneurial intentions may emerge. Based on this, this paper puts forward the following hypotheses:

H4: Perceived expectation will be positively related to their entrepreneurial intention.

H5: Perceived feasibility will be positively related to their entrepreneurial intention.

\section{The mediating role of perceived expectation and perceived feasibility}

Shapero \& Sokol noted that entrepreneurship education could promote the perceived expectation and feasibility of potential entrepreneurs without making explicit validation in terms of the correlation [5]. The study of Zhang et al. found that the background of entrepreneurship education had a significant indirect influence on entrepreneurial intention through three antecedent variables of entrepreneurial event model. However, when introducing the variable of entrepreneurship education, the research found that the indirect influence disappeared [7]. This paper argues that whether the entrepreneurship education can effectively stimulate the entrepreneurial intention depends on whether it can promote the perceived expectation and feasibility effectively, that is to say, the impact of entrepreneurship education on the entrepreneurship intention is achieved by influencing on the entrepreneurship perceived expectation and feasibility of college students. Based on this, this paper gives following hypotheses:

H6: perceived expectation plays a mediating role in the relationship between entrepreneurship education and entrepreneurial intention.

H7: perceived feasibility play a mediating role on the relationship between entrepreneurship education and entrepreneurial intention.

\section{EMPIRICAL ANALYSIS}

\section{A. Sample and Data Collection}

This study obtains the data by using questionnaire methods. From April to June of 2014, 812 questionnaires were sent out and 421 were gotten after discriminating the validities. The distributions of sample characteristics are as follows: The gender of the subjects: male accounts for $32 \%$ and female accounts for $68 \%$; age: the students under 20 occupies $4.4 \%$, 20-25, 74.3\%; 26-30, 19.4\%, older than 30, 1.9\%. Education background: junior degree accounts for $16.5 \%$, bachelor degree, 62.6\%; master degree, $19.4 \%$; doctor degree $1.5 \%$. Distribution of specialty: students majoring in science and engineering, $23.4 \%$, economics and management 51\%, humanities $14.6 \%$.

\section{B. Variable Measurement and Test for Reliability and Validity of Scale}

The scales for measuring entrepreneurship education, perceived expectation and feasibility and entrepreneurial intention are based on the studies of Fayolle and Klandt [8], Krueger et al.[9] and Franke and Lüthje [10]. The reliabilities of these variables are $0.899,0.823,0.753$ and 0.835 , and the Cronbach's Alpha coefficient values are generally above 0.7 with higher level. Moreover, the CITC values of all the operational variables are more than 0.5 , illustrating a preferable reliability. The KMO test coefficients of the entrepreneurship education scale, the perceived expectation scale, the perceived feasibility scale and the entrepreneurial intention are respectively $0.896,0.702,0.705$ and 0.830 , which shows that the scales are suitable for factor analysis.

\section{DATA ANALYSIS AND RESUlts}

\section{A. Descriptive Statistics}

All the variables have smaller variance and bigger mean value, showing that the data has the characteristics of polarization and less variation. As for the correlation coefficients, the entrepreneurship education always has a significantly positive correlation with the perceived feasibility $(\mathrm{r}=0.245, \mathrm{p}<0.05)$ and the entrepreneurial intention $(\mathrm{r}=0.198, \mathrm{p}<0.05)$ which indicates the positive correlation relationship with different degrees; the perceived expectation and the entrepreneurship intention $(r=0.566, p<0.05)$, the perceived feasibility and the entrepreneurship intention $(\mathrm{r}=0.491, \mathrm{p}<0.05)$ are also significantly positive correlated with each other; whereas there is no significant correlation between the entrepreneurship education and the perceived expectation( $\mathrm{r}=0.091, \mathrm{p}>0.01)$, which shows a negligible effect of the education on the expectation. As a consequence, the results of correlation analyses have provided preliminary support for part of the theoretical assumptions, which lays a foundation for the subsequent empirical test.

\section{B. Hypotheses Testing}

The study used three-step test method to examine the intermediary roles of the perceived expectation and the perceived feasibility. Table 2 show the relationship between the entrepreneurship education and the entrepreneurial intention $(\beta=0.198, p<0.001)$ is significantly positive correlated (as is 
shown in model 3); the influence of entrepreneurship education on the perceived expectation $(\beta=0.091, p=0.191)$ is not significant (as is shown in model 1); entrepreneurship education has a significantly positive influence $(\beta=0.245, p<0.001)$ on the perceived feasibility (as is shown in model 2).Therefore, hypothesis 1 is confirmed; however, hypothesis 2 is not verified. In the meanwhile, due to the intermediary role simultaneously satisfies the correlation between the independent variables and dependent variables, the independent variables and intermediary variables, the invalid hypothesis 2 can infer the false hypothesis 6 . Hypothesis 3 that the entrepreneurship education has a positive correlation with the perceived feasibility is established.

TABLE I. THE RESULT OF REGRESSION ANALYSIS

\begin{tabular}{|c|c|c|c|c|c|c|}
\hline Variables & The Perceived Expectation & The Perceived Feasibility & \multicolumn{4}{|c|}{ Entrepreneurship Intention } \\
\hline Model & Model 1 & Model 2 & Model 3 & Model 4 & Model 5 & Model 6 \\
\hline Entrepreneurship Education & 0.091 & 0.245 & 0.198 & & & 0.082 \\
\hline The Perceived Expectation & & & & 0.566 & & \\
\hline The Perceived Feasibility & & & & & 0.491 & 0.471 \\
\hline $\mathrm{N}$ & 421 & 421 & 421 & 421 & 421 & 421 \\
\hline $\mathrm{R} 2$ & 0.008 & 0.060 & 0.039 & 0.320 & 0.241 & 0.248 \\
\hline The overall adjusted R2 & 0.003 & 0.056 & 0.034 & 0.316 & 0.238 & 0.240 \\
\hline $\mathrm{F}$ & 1.718 & $13.080 * * *$ & $8.317 * * *$ & $95.908 * * *$ & $64.906 * * *$ & $33.425 * * *$ \\
\hline
\end{tabular}

In the regression result of the dependent variables effecting on the intermediary variables, the perceived expectation has a significantly positive influence $(\beta=0.566, p<0.001)$ on the entrepreneurial intention (as is shown in model 4). The perceived feasibility has a significantly positive influence $(\beta=0.491, p<0.001)$ on the entrepreneurial intention (as is shown in model 5). Therefore, hypothesis 4 that there is a positive correlation between the perceived expectation and the entrepreneurial intention is established through the test. Hypothesis 5 that there is a positive correlation between the perceived feasibility and the entrepreneurial intention is also confirmed.

TABLE II. THE RESULT OF REGRESSION ANALYSIS OF THE INTERMEDIARY VARIABLES

\begin{tabular}{|c|c|c|c|c|c|c|c|c|}
\hline & \multirow{2}{*}{ Model } & \multicolumn{2}{|c|}{ Unstandardized coefficients } & \multirow{2}{*}{$\begin{array}{c}\text { Standardized coefficients } \\
\beta\end{array}$} & \multirow{2}{*}{$\mathrm{t}$} & \multirow{2}{*}{ Sig. } & \multicolumn{2}{|c|}{ The statistics of multicollinearity } \\
\hline & & B & Standard error & & & & Fault- tolerant & VIF \\
\hline \multirow{2}{*}{1} & Constant & 2.601 & 0.260 & & 9.995 & 0.000 & & \\
\hline & Entrepreneurship Education & 0.228 & 0.079 & 0.198 & 2.884 & 0.004 & 1.000 & 1.000 \\
\hline \multirow{3}{*}{2} & Constant & 1.477 & 0.275 & & 5.367 & 0.000 & & \\
\hline & Entrepreneurship Education & 0.095 & 0.072 & 0.082 & 1.310 & 0.192 & 0.940 & 1.064 \\
\hline & The Perceived Feasibility & 0.550 & 0.073 & 0.471 & 7.502 & 0.000 & 0.940 & 1.064 \\
\hline
\end{tabular}

Given the significant influence of entrepreneurship education on the perceived intention, the study introduced the perceived feasibility as the variable (as is shown in model 6, table 2). The influential effect of entrepreneurship education on entrepreneurial intention has reduced $(\beta=0.082)$ and F-statistic is significant $(p<0.001)$. Therefore, the perceived feasibility plays an intermediary role in the relationship between entrepreneurship education and entrepreneurial intention. In the regression result of the intermediary variables in table 3 , we also see that the education has negligible influence on the intention ( $\mathrm{p}=0.192)$ with introducing the perceived feasibility. This suggests that the perceived feasibility plays a completely intermediary role in the entrepreneurship education and the entrepreneurial intention. Therefore, the assumption 7 is established.

\section{CONCLUSION AND IMPLICATIONS}

Firstly, it is an effective way to promote college students' entrepreneurship by developing entrepreneurship education. Although the entrepreneurship rate of college graduates remains a low level of $1 \%$, it is too hasty to deny the validity of the entrepreneurship education. As a matter of fact, there exists a time lag in the effect of entrepreneurship education. This paper indicates that the entrepreneurship education of colleges and universities has a significantly positive correlation with the entrepreneurial intention, which suggests that in China, 
entrepreneurship education did promote college students' entrepreneurial motivation. Although most of the college students say they will not be engaged in entrepreneurship immediately after their graduation, they might start their own business at a time in the future.

Secondly, perceived feasibility plays a completely intermediary role between the entrepreneurship education and the entrepreneurial intention. In the interviews with students who have strong entrepreneurial intentions, most of them mentioned the vigorous influence of schools' entrepreneurship education forms, such as the entrepreneurship stimulated training, incubation projects as well as successful experience sharing, consulting and guidance. Through these training programs, students could advance their skills, enhance the comprehensive understanding and personal experience, and then raise subjective perception of the entrepreneurial feasibility. We did find some students drop the original idea of starting up business, which seemed to confirm the viewpoint that entrepreneurship education may decrease the entrepreneurial intention. Nevertheless, after making a further investigation, the reason why students do so is that during the education of entrepreneurship, they are more aware that it is difficult to be successful without the qualities and abilities needed for entrepreneurship. On the basis of the conclusion of this study, it virtually results from that entrepreneurship education lowers the subject perception of entrepreneurial feasibility. It is observed that why the previous scholars draw different conclusions in terms of the influence relation between the entrepreneurship education and the entrepreneurial intention is because of the lack of understanding and demonstration of the influence mechanism. This study makes up for the shortage and proves that only with the efficient improvement of students' subject perception for entrepreneurial feasibility can it promote the emergence of entrepreneurial intention. It undoubtedly pointes out the direction for designing the entrepreneurship education's course content, method and pattern in domestic colleges and universities.

Thirdly, this study proved the positive influence of the perceived expectation on the entrepreneurial intention, but there is negligible effect of the entrepreneurship education on the perceived expectation. In China, perceived expectation is more influenced by families, personal characteristics, cultural and so on. The study found the entrepreneurial experiences of relatives positively influenced the perceived expectation of college students. In addition, students grown in southern China are more entrepreneurial than those in northern China. This paper believed the low perceived expectation of entrepreneurship is the main reason for the low entrepreneurship rate. Although entrepreneurship education can improve college students' subjective perception for entrepreneurial feasibility, supposing that students have very low perceived expectation, it wouldn't result in entrepreneurial intention and activities. Since entrepreneurship education are limited in improving college students' perceived expectation, local governments, enterprises, communities and universities should cooperate with each other to create an ecological system of entrepreneurship education, build the entrepreneurial culture as well as the entrepreneurial environment and facilitate the formation of entrepreneurial perceived expectation in the future.

\section{ACKNOWLEDGEMENT}

This research was financially supported by the National Social Science Foundation of China (Grant No.12BGL048), Funds of Education Department of Liaoning Province, China (Grant No. WR2013013) and Economic and Social Development Research Project of Liaoning Province (Grant No. 2016lslktziglx-08).

\section{REFERENCES}

[1] T.V. Menzies and J.C. Paradi, Entrepreneurship education and engineering students career path and business performance, International Journal of Entrepreneurship \& Innovation, vol. 4(2), pp. 121-132, 2003.

[2] J. Chamard, Public education: Its effect on entrepreneurial characteristics. Journal of Small Business \& Entrepreneurship, vol. 6(2), pp. 23-29, 1989

[3] A. Fayolle, B. Gailly and N. Lassas-Clerc, Assessing the impact of entrepreneurship education programs: A new methodology. Journal of European Industrial Training, 2006, vol.30(9): 701-720.

[4] N. F. Krueger, and A. L. Carsrud, Entrepreneurial intentions: Applying the theory of planned behaviour. Entrepreneurship \& Regional Development, vol.5(4) , pp. 315-330, 1993.

[5] A. Shapero and L. Sokol, The social dimensions of entrepreneurship, C.A. Kent, D.L. Sexton, and K.H. Vesper, Encyclopedia of Entrepreneurship, Englewood Cliffs, NJ: Prentice-Hall, pp. 72-90, 1982.

[6] M. Guerrero, J. Rialp and D. Urbano, The impact of desirability and feasibility on entrepreneurial intentions: A structural equation model. International Entrepreneurship \& Management Journal, vol. 4(1) , pp. 35-50, 2008.

[7] Y Zhang, G. Duysters and M. Cloodt, The roles of entrepreneurship education as a predictor of university students' entrepreneurial intention, International Entrepreneurship \& Management Journal, vol.10(3) , pp. 119, 2013.

[8] A. Fayolle and H. Klandt, International entrepreneurship education: Issues and newness, Cheltenham: Edward Elgar Publishing, 2006.

[9] N.F. Krueger, M.D. Reilly, and A.L. Carsrud, Competing models of entrepreneurial intentions, Journal of Business Venturing, vol.15, pp. 411-432, 2000.

[10] N. Franke and C. Lüthje, Entrepreneurial intentions of business students: A benchmarking study, International Journal of Innovation and Technology Management, vol.1(3) , pp. 269-288, 2004. 